\section{FROM THE DESK OF THE RESIDENCY PROGRAM DIRECTOR}

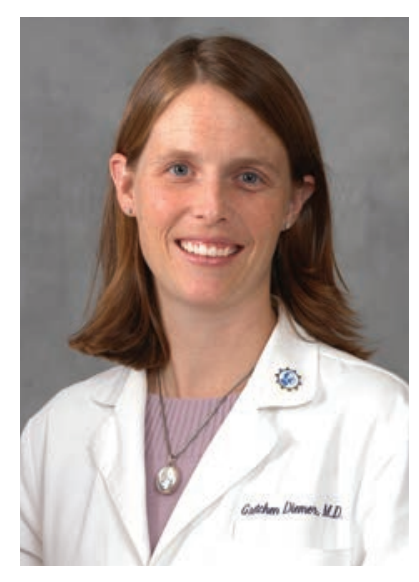

\section{Welcome to the Forum!}

We have experienced another wonderful year in the Jefferson Internal Medicine Residency Program! Our program continues to attract the best and brightest medical students who over three years become outstanding clinicians, accomplished researchers and compassionate physicians. Residency training is increasingly complex, with competing demands compressing their work into fewer hours. I am consistently impressed with the camaraderie among our housestaff-they not only take care of patients, but they take care of each other. It is something that sets our program apart from others and is something of which I am incredibly proud.

Like every year, this year has come with changes. Besides being one of the worst winters on record in Philadelphia and having a hospital that was often bursting at the seams with patients, the Next Accreditation System from the ACGME was implemented. This has shifted the way residency programs are accredited and prompted us to overhaul our evaluation system for residents. Our patient safety and quality improvement curriculum began this year with great success and the housestaff have embraced it. We have already seen results from improvement cycles and engagement into systems changes resulting in delivery of better care to our patients. Our residents know this hospital inside and out and are in a great position to be the leaders we need in quality improvement and patient safety at Jefferson.

Our residents have put together yet another outstanding journal showcasing their academic interests and humanistic talents. I hope you will enjoy reading it!

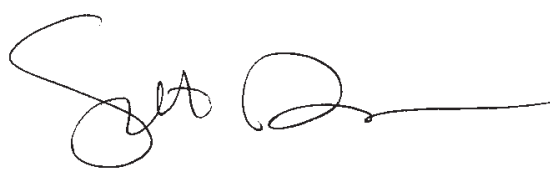

Gretchen Diemer, MD, FACP Assistant Professor of Medicine Program Director 